\title{
A Study of Cost incurred in providing Emergency Care Services in an Apex Tertiary Care Hospital
}

\author{
${ }^{1}$ Neeraj Garg, ${ }^{2}$ Shakti K Gupta, ${ }^{3}$ Amit Lathwal, ${ }^{4}$ Ruchi Garg
}

\begin{abstract}
Introduction: An emergency department (ED), also known as accident and emergency (A\&E), emergency room (ER), or casualty department, is a medical treatment facility specializing for acute care of patients who present without prior appointment, either by their own means or by ambulance. In spite of the emergency beds forming only a fraction of the hospital beds, they consume a relatively large proportion of the hospitals resources. There is a requirement to ascertain the cost incurred in providing emergency care treatment to the patients coming to an apex tertiary care center, whose principal mandate is to provide tertiary care treatment. The study will not only help in allocating funds to the ED in an apex tertiary care facility but will also be useful if the hospital authorities decide to outsource the emergency services to a third party.
\end{abstract}

Aims and objectives: To study the cost incurred in providing emergency care services in an apex tertiary care hospital. To identify the various cost centers pertaining to patient care in the emergency care department and to estimate the cost of rendering patient care in ED and the cost of running the emergency per day.

Materials and methods: Six months' retrospective data were collected from the ED, accounts section, engineering section, stores department, radiology department, emergency lab, computer facility, etc. The cost was apportioned to per patient as well per hour in rendering emergency care services.

Observations: The total cost incurred in providing emergency care services in the hospital under study was Rs 2034 per patient, while Rs 31,000 are spent per hour in running the emergency care facility.

Discussion: Almost 40 to $50 \%$ of the total cost incurred on providing emergency care services goes to the salary head of the staff working in the ED. The next major sources of expenditure are the radiology and lab investigations.

Conclusion: The study suggests that a considerable amount of hospital funds are spent on providing emergency care services in the apex tertiary care facility, whose primary mandate

\footnotetext{
${ }^{1}$ Lieutenant Colonel, ${ }^{2}$ Medical Superintendent, ${ }^{3}$ Assistant Professor, ${ }^{4}$ Senior Resident

${ }^{1} \mathrm{MOHS}$, Army Hospital (Research and Referral), New Delhi India

${ }^{2} \mathrm{Dr}$. RP Centre of Ophthalmic Sciences, All India Institute of Medical Sciences, New Delhi, India

${ }^{3,4}$ Department of Hospital Administration, All India Institute of Medical Sciences, New Delhi, India

Corresponding Author: Ruchi Garg, Senior Resident Department of Hospital Administration, All India Institute of Medical Sciences, New Delhi, India
}

is to provide tertiary care services. The possibility of complete outsourcing or partial outsourcing in the form of radiology investigations and hiring humanpower on a contract basis can be a viable solution, to reduce the cost on providing emergency care, which can better be utilized in providing high-end tertiary care facilities.

Keywords: Accident and emergency, Tertiary care hospital, Unit cost.

How to cite this article: Garg N, Gupta SK, Lathwal A, Garg R. A Study of Cost incurred in providing Emergency Care Services in an Apex Tertiary Care Hospital. Int J Res Foundation Hosp Healthc Adm 2016;4(1):45-50.

\section{Source of support: Nil}

\section{Conflict of interest: None}

\section{INTRODUCTION}

An emergency department (ED), also known as accident and emergency (A\&E), emergency room (ER), or casualty department, is a medical treatment facility specializing in acute care of patients who present without prior appointment, either by their own means or by ambulance. The ED is usually found in a hospital or other primary care center.

The ED of most hospitals operate 24 hours a day, although staffing levels may be varied in an attempt to mirror patient volume.

Due to the unplanned nature of patient attendance, the department must provide initial treatment for a broad spectrum of illnesses and injuries, some of which may be life threatening and require immediate attention. In some countries, emergency departments have become important entry points for those without other means of access to medical care.

In the hospital where this study has been undertaken, there are three emergencies, i.e., medical, surgical, and pediatrics. The annual attendance to the emergency is around 1,35,000, with approximately 330 to 350 patients coming to the ED. There are 88 beds in total divided in three wards, for inpatients admitted through emergency, and total 53 beds for observation of patients in all the three emergencies. There is further a provision to accommodate patients on trolleys during exigencies.

The health expenditure in India was less than $1 \%$ of the GDP in the eleventh plan period. It has since been increased to $1.3 \%$ during the year $2015-16$ and is slated to rise both as a proportion of the GDP and in absolute 
numbers. This has led to the government looking toward the private sector to augment the health care delivery system through suitable models of partnership. Health care resources are sparse and the need for the same is unmet to a large extent. The out-of-pocket expenditure incurred by a patient in India at present is estimated at about 70 to $80 \%$.

Emergency services are provided free of cost in government hospitals and as such have no budgetary allocation or control. In a resource-poor setting, the need for a costing study cannot be overemphasized. Provision of health care costs money to the government and individuals. Hospital care incurs considerable costs. Emergency care costs many times more than general hospital beds. In spite of the emergency beds forming only a fraction of the hospital beds, they consume a relatively large proportion of the hospitals resources. Numerous studies point to the fact that hospital emergencies cost 10 to $40 \%$ out of the total hospital costs. The need for reimbursing the private players in this circumstance becomes an issue in the light of lack of reliable costing data for care. It is obvious that the basic assessment and knowledge of economics is essential to increase the economic efficiency, and costing studies are one useful way of understanding these.

Such studies will help hospital (ED) planners, administrators, and health department in

- Allocating resources for current operations of ED

- Planning of new ED or expansion of existing ED services

- Calculating/setting charges for Emergency care

- Reimbursement/insurance

- Budget projections

\section{Approaches of Costing}

With regard to costing methodologies, there are four methods that one can use to allocate costs to a patient. ${ }^{1}$

1. First, an investigator can use surrogates for cost, such as charges or prices, either unadjusted or adjusted for a cost-to-charge ratio, linking these to each patient. In the other three methods, investigators directly measure costs rather than using surrogate measures, such as charges.

2. In the second method (called process or "top down" costing), investigators measure all the relevant costs in each cost center and divide this total by either the number of service units (e.g., patient days) or the weighted service units (e.g., TISS units, or the Therapeutic Intervention Scoring system) to obtain a cost per (weighted) unit. Total per-patient costs are equal to cost per (weighted) service times the number of (weighted) services.
3. In the third method (called job, bottom-up, or microcosting), the investigator traces each resource (e.g., nursing time) to each patient, provides a cost for the resource, and adds up the cost for each patient.

4. In the fourth method (called activity-based costing), the investigator develops a comprehensive list of activities (e.g., providing ventilation services), develops a standard unit cost for each, and then develops a cost for each patient according to the activities that were used in the care of each patient.

\section{Activity-based Costing}

Activity-based costing $(\mathrm{ABC})$ is an economic model that identifies the cost pools or activity centers in an organization and assigns costs to cost drivers based on the number of each activity used. Since the cost drivers are related to the activities, they occur on several levels: ${ }^{2,3}$

- Unit-level drivers, which assume the increase in the inputs for every unit that is being produced.

- Batch-level drivers, which assume the variation of the inputs for every batch that is being produced.

- Product-level drivers, which assume the necessity of the inputs to support the production of each different type of product.

- Facility-level drivers, which are related to the facility's manufacturing process. ${ }^{4}$

Users of the $\mathrm{ABC}$ system will need to identify the activities that generate cost and then match the activities to the level bases used to assign the products. While using the $\mathrm{ABC}$ system, the activities that generate cost must be determined and then should be matched to the level drivers used to assign costs to the products.

Information generated by ABC significantly contribute to hospital management in planning and managerial control, as they enable organizational behavioral changes by enhancing the attention focus for activities due to volumes. Application of the ABC in health care institution entails a number of predictable benefits, especially the ability to quantify the actual costs of activities, to identify the relationship between the costs and means of carrying out these activities, to identify capacity influences on the overall costs of the organization, and to assess legislative issues regarding the reimbursement of particular performances to also measure the "profitability" of provided operations. $^{2}$

An alternative approach for estimating an ABC model is called "time-driven activity-based costing." It is simpler, less costly, and faster to implement, and allows cost driver rates to be based on the practical capacity of the resources supplied. The essence of ABC and activitybased management is the measurement and management of the organization's capacity. For this purpose, ABC systems require two estimates: ${ }^{5}$ 
1. The unit cost of supplying capacity, and

2. The consumption of capacity (unit times) by the activities the organization performs for products, services, and customers.

The traditional ABC system overestimates the costs of performing activities because of its distribution of effort survey. By specifying the unit times to perform each instance of the activity, the organization gets both a more valid signal about the cost and the underlying efficiency of each activity as well as the quantity and cost of the unused capacity in the resources supplied to perform the activity. Another benefit of implementing a time-driven ABC model is the knowledge it generates about the efficiencies - unit cost and unit times - of critical business processes. Managers are often surprised by how much time it takes to process a special order or to set up a new customer or the costs of performing a quality assurance check. Companies have enjoyed immediate benefits from their models by focusing their improvement efforts on high-cost and inefficient processes.

As per a study done by Dr Michael Lee, assistant professor of emergency medicine in the Warren Alpert Medical School of Brown University and a physician at Rhode Island Hospital and the Miriam Hospital, on the cost of EMS services in U.S. Hospitals, ED costs are between 4.9 and $5.8 \%$ of the total healthcare spending. Across four major studies over the last three decades, the average cost per patient of an ED visit in 2010 ranged from only $\$ 134$ to more than $\$ 1000$, as found by Lee and colleagues. ${ }^{6}$

\section{Elements of Costing}

\section{Manpower}

- Direct manpower also known as process labor, productive labor, etc., is one that actively or directly takes part in the production of a commodity.

- Indirect manpower is the labor employed for carrying of tasks incidental to the goods produced or services provided.

\section{Material/Resources}

- Direct material is one that becomes an integral part of a finished product and can be conveniently assigned to a specific physical unit.

- Indirect material is one that cannot be conveniently and wholly allocated to a specific cost center. The material that is used for purposes ancillary to the business and that cannot be conveniently assigned to specific physical units is termed as indirect material. Consumable stores, oil and waste, printing and stationery material, etc., are some of the examples of indirect material.

\section{Expenses}

- Direct expenses are those that can be wholly and directly allocated to the goods produced or to the service rendered. For example, the cost of buying the equipment or the gases for the cylinders.

- Indirect expenses, for example, water or electricity charges, which cannot be directly allocated to the expenses incurred. Overhead costing is a term used to refer to the indirect elements of costing.

The guidelines of the internal revenue service (Washington, D.C.: U.S. Govt. Printing Office 1963) estimates the life of office furniture, fixtures, machines, and equipment at 10 years and they would depreciate at the rate of $10 \%$ per annum. ${ }^{2}$

\section{MATERIALS AND METHODS}

Study design: Descriptive, cross sectional, retrospective, record-based study

Study period: Six months' retrospective data was studied. Data collection: Data were collected respectively from the ED, accounts section, engineering section, stores department, radiology department, emergency lab, computer facility, etc.

Data analysis: Data analysis was done using Microsoft Excel 2010.

Cost ascertainment process: The cost centers (cost heads) were identified and data pertaining to each were collected under the following heads. Traditional method of costing was used for cost estimates as follows.

\section{Cost Centers (Cost Heads)}

\section{Estates}

This included

- Capital cost of the building: The replacement cost of the building was calculated based on the historical value, and the Cost Inflation Index $(\mathrm{CII})^{7}$ correction was applied. Annualization factor was applied to evaluate the cost of the facility for the financial year 2012 to 2013 (the study period) as per the WHO costing manual. ${ }^{4}$

- Annualization: The annualization of the costs was used as the standard methodology to arrive at the current capital costs. This involved the following steps as elaborated in the WHO Manual for Hospital Costs-A Manual for Managers by Shepard et al. ${ }^{4}$

- The cost of building was ascertained as per CPWD manual rates for 2014, based on the rates per square meter. ${ }^{8}$ The total area of emergency as per the drawings of the Engineering Department is $1950 \mathrm{sq} \mathrm{m}$.

- The cost of building in 2007 was multiplied by the inflation factor obtained by the ratio of the common inflation index of the present financial 
year (FY) to the inflation index of year 2007 to arrive at or calculate the replacement cost of the present FY.

- The current capital cost was divided by 100, considering the life of building as 100 years as per WHO manual, to get the annualization value.

- The cost of electrical installations and water and sewerage work was calculated as above.

- The cost of heating ventilation air conditioning (HVAC) was calculated by taking the basic cost, maintenance cost, operational cost, and cost of electricity incurred on running the HVAC. The capital cost of the plant and the air handling units (AHUs) were noted from records and the replacement cost was calculated by multiplying with CII. Annualization value was obtained by dividing with 10 , considering the average working life as 10 years. Maintenance cost was apportioned based on the tonnage used in emergency. Operational cost was derived from the salaries of the AHU operators who are dedicated for emergency. And the cost of electricity consumed for running was ascertained based on the hours of operation daily and the tonnage of plant and AHUs.

- Cost of maintenance: The actual maintenance cost for the financial year 2012 to 2013 was obtained. The emergency area proportionate to the total area of the main hospital was used as the apportioning criteria. The maintenance cost was calculated for the emergency as a proportion of the total maintenance cost.

- Cost of electricity: The cost of electricity consumption was ascertained by calculating the total number of electrical appliances and multiplying with the wattage and daily running.

\section{Manpower}

- Doctors

- Nurses

- Technicians

- Security staff

- Housekeeping staff

Midpoint salary based on the revised pay scales as per the Sixth Pay Commission was taken for calculating the cost of the manpower to the emergency. The faculty cost was apportioned depending on the hour spent in the emergency. The indirect manpower for various support services is covered under the respective support services cost.

\section{Support Services, Clinical}

- Laboratory and blood bank - the laboratory cost per test of the emergency as well the cost of one unit of blood/blood component bag was assumed based on the cost provided by a previous study conducted in year 2012 by Dr Sunil Verma. The total number of hematology and biochemistry tests conducted for patients in emergency were obtained from the emergency lab, and accordingly the cost incurred on lab investigation from emergency was calculated. Similarly, the total number of blood products transfused to emergency patients were obtained from the records of the ED, and accordingly the cost was obtained by multiplying the number of blood products transfused with the cost of each component.

- Radiology cost has been estimated as per the cost of similar investigations being charged from private ward patients, who pay for the investigation. The number of tests conducted on patients sent from emergency was obtained from the radiology department and accordingly cost incurred on radiological investigation was ascertained.

- Manifold cost is taken from the previous costing study of manifold services conducted by Dr P Kumar in the year 2010. The per-point cost is multiplied with the total number of points after doing cost inflation index adjustment.

\section{Support Services, Nonclinical}

- Central sterile supply department (CSSD) and laundry - the cost of the CSSD and laundry has been ascertained from the previous study conducted by Dr Shilpi Verma in the year 2012, and the same has been used for computing the cost of CSSD and laundry for the emergency.

- Housekeeping staff dedicated to the emergency has been included in the manpower cost and the consumable has been included in the stores valuation. The cost has been brought down to per-patient cost.

- Security - the cost of the security personnel has been included in the manpower cost of the emergency.

- Ambulance - the cost of the three ambulances used was taken from the ambulance section. Daily petrol/ diesel consumption and the cost of maintenance was also obtained from the records of ambulance section. Drivers' salary was also considered before deriving the per-patient cost on ambulance services.

- Cost of bio medical waste management (BMW) is ascertained by dividing the total contract value/year with no of collection points. The per-point collection rate is multiplied with the number of points in emergency.

- Medical social service officer (MSSO) - salaries of three MSSO, dedicated for casualty, were considered for deriving the cost incurred on MSSO services. 


\section{Consumables}

- Drugs and surgical consumables

- General stores

- Stationary

- Linen

The consumption for a 6-month period was taken into account and the rates for the same were fixed as per the rate contracts from the store section. Further, the cost of consumables per patient was calculated. Consumable items were on rate contract and therefore, there was no fluctuation of values during the study period.

\section{OBSERVATIONS}

Summary of cost under major heads:

\begin{tabular}{lll}
\hline Sl. no. & Cost head & Cost per patient \\
\hline 1 & Estate & 144.5 \\
2 & Manpower & 957 \\
3 & Medical equipment and consumables & 301.7 \\
4 & Support services clinical & 583.81 \\
5 & Support services nonclinical & 46.9 \\
\hline & Total & 2034.11 \\
\hline
\end{tabular}

Total cost/year $=$ Rs 27,15,53,685.

Twenty-seven crore fifteen lac fifty-three thousand six hundred eighty-five rupees are spend annually on running all the three casualties. And Rs 2034.11 is spent in providing emergency treatment per patient.

\section{SUMMARY}

Summary of all cost centers is given under Table 1 .

Total cost/year $=$ RS 27,15,53,685

Total cost/day $=$ Rs 7,43,982.7

Total cost/hour $=$ Rs 30,999.27

Total cost/patient $=$ Rs 2034.11

\section{DISCUSSION}

The distribution of expenditure under various cost head is reflected in Pie Chart 1. As per the study done by Dr Michael Lee, Assistant Professor of Emergency Medicine in the Warren Alpert Medical School of Brown University and a physician at Rhode Island Hospital and the Miriam Hospital, on the cost of EMS services in U.S. Hospitals, ED costs are between 4.9 and $5.8 \%$ of total healthcare spending. ${ }^{6}$

In our study, the total cost/year came to around 27 crore rupees. The total fund allocated to the hospital under study in that particular year was 426 crore rupees. Thus, $6.35 \%$ of the total expenditure of the hospital goes in providing emergency care services. Almost 40 to $50 \%$ of the total cost incurred on providing emergency care services
Table 1: Summary of all cost centers

\begin{tabular}{rlll}
\hline Sl. & Summary of the total cost & & \\
no. & per patient & Cost (Rs) & Percentage \\
\hline 1 & Building & 8.6 & 0.4 \\
2 & Central air conditioning & 101.9 & 5 \\
3 & Laboratory & 136.5 & 6.7 \\
4 & Electricity & 34 & 1.6 \\
5 & Ambulance & 15 & 0.7 \\
6 & Equipment & 63 & 3.1 \\
7 & Instruments & 0.6 & 0.03 \\
8 & Items from computer facility & 1.9 & 0.1 \\
9 & Drugs & 212 & 10.4 \\
10 & Manifold & 3.85 & 0.2 \\
11 & MSSO & 9 & 0.4 \\
12 & BMW & 4.2 & 0.2 \\
13 & Stationary & 9.4 & 0.4 \\
14 & Linen Stores & 3.8 & 0.2 \\
15 & General Stores & 12.9 & 0.6 \\
16 & Manpower & 957 & 47 \\
17 & Laundry Services & 13 & 0.6 \\
18 & Blood Bank Services & 77.3 & 3.8 \\
19 & Radio-imaging services & 366.16 & 18 \\
20 & CSSD & 4 & 0.2 \\
\hline & Total & 2034.11 & 100 \\
\hline
\end{tabular}

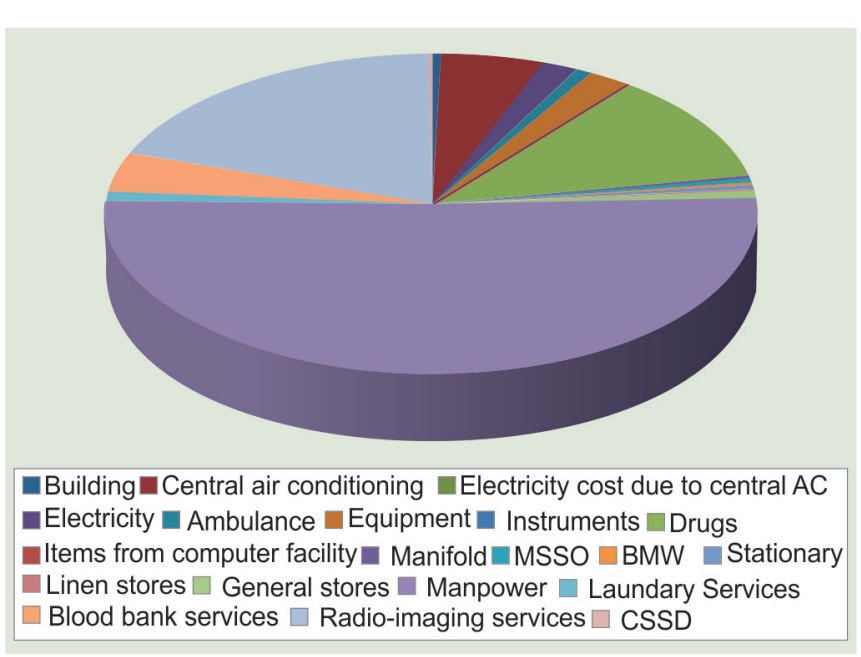

Pie Chart 1: Distribution of expenditure

goes to the salary head of the staff working in the ED. The next major source of expenditure are the radiology and lab investigations.

\section{CONCLUSION}

The study suggests that a considerable amount of hospital funds are spent on providing emergency care services in the apex tertiary care facility, whose primary mandate is to provide tertiary care services. The possibility of complete outsourcing or partial outsourcing in the form of radiology investigations and hiring manpower on a contract basis can be a viable solution, to reduce the cost on providing emergency care, which can better be utilized in providing high-end tertiary care facilities. 


\section{REFERENCES}

1. Kurup HKK. On the estimation of hospital cost: The approach. Centre for Development Studies (JNU), Kerala, India. 1993.

2. Kaplan RS, Anderson SR. Time-driven activity-based costing. Harv Bus Rev 2004 Dec;82(11):131-138, 150.

3. Udpa S. Activity-based costing for hospitals. Health Care Management Review. 1996 21(3), 83-96.

4. Shepard, D.S., Hodgkin, D., Anthony, Y.E., World Health Organization,. Analysis of Hospital Costs: a Manual for Managers. Geneva: World Health Organization, 2000.
5. Popesko BRC. Application of ABC Method in Hospital Management BORIS POPESKO Department of Enterprise Economics Tomas Bata University in Zlín nám. TG Masaryka. 2011; p. 73-78.

6. Are emergency care cost estimates too low? Brown University News and Events [Internet]. [cited 2013 Aug 30]. Available from: http://news.brown.edu/pressreleases/2013/04/emergency

7. Cost Inflation Index Chart - Capital Gain 1981 - 2014 [Internet]. [cited 2013 Sep 17]. Available from: http://cadiary. org/cost-inflation-index-capital-gain/

8. Plinth Area Rate. Annex 1. CPWD Works Manual GOI . 2014. p. 3-8 